\title{
Une forme d'autisme liée à un déficit enzymatique
}

Les nouvelles de ce numéro ont été préparées par : J.C. Dreyfus J.P. Grunfeld A. Kahn

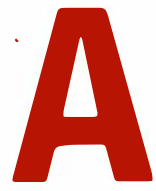

utour de l'autisme infantile se tissent inévitablement des controverses passionnées - comme en témoigne une récente enquête d'un grand quotidien du soir - où se heurtent parents, psychologues, psychanalystes, biologistes. Les efforts de ces derniers ne sont pas encore parvenus à apporter des données décisives et reproductibles. C'est pourquoi nous souh aitons souligner les résultats obtenus dans un laboratoire belge, qui s'est déjà signalé par nombre de découvertes en pathologie enzymatique. L'étude portait sur trois enf ants de 2 à 4 ans, porteurs de troubles psychomoteurs comportant des manifestations autistiques; l'un des enfants est belge, de parents non apparentés; les deux autres, marocains, sont frère et sœur, de parents consanguins, suggérant une hérédité récessive autosomique.

Dans le plasma, l'urine et le liquide céphalorachidien, on a trouvé une accumulation anormale de deux métabolites, succinyladénosine et le succinylaminoimidazole carboxamide riboside. Ces deux composés possèdent deux points en commun. D'abord, ils sont tous deux attaqués par une même enzyme, l'adénylosuccinase. On a donc été amené à doser cette enzyme, encore mal connue, dans tous les tissus accessibles; les résultats ont fait penser qu'il en existe plusieurs isozymes. Son activité est en eff et normale dans les cellules sanguines et le muscle, mais effondrée dans le foie et surtout dans le rein. L'enzyme est sans doute altérée aussi dans le cerveau (où elle n'a pu être dosée) car c'est dans le liquide céphalorachidien que l'élévation des métabolites est la plus forte. Ensuite, ces composés sont tous deux des étapes de la voie de synthèse de novo des purines. On sait que la biosynthèse des nucléotides à purine peut emprunter deux voies : l'une, dite d'épargne ou de ré-utilisation, part des purines déjà synthétisées, alimentaires par exemple; son importance est attestée par le fait que le déficit en une des enzymes, l'hypoxanthine phosphoribosyltransférase (HPRT) conduit aux conséquences neurologiques désastreuses du syndrome de Lesch-Nyhan. L'autre voie, endogène, est très complexe puisqu'elle comporte une douzaine d'étapes. On n'en connaît, à ce jour, aucun déficit, mais on peut concevoir qu'il puisse en exister et que les conséquences en soient redoutables.

Les conclusions provisoires du travail seraient les suivantes : certains tissus subiraient un déficit en adénylosuccinase, le foie, le rein, le cerveau probablement aussi. Les dommages qui en résulteraient pourraient être dus, soit à l'accumulation de substances toxiques, soit à une synthèse insuffisante de nucléotides et d'acides nucléiques, cérébraux en particulier, que la voie d'épargne ne suffirait pas à compenser.

Il ne s'agit nullement de prétendre que la lésion biochimique de l'autisme a été élucidée. Les auteurs prennent soin de parler d'" un sous-groupe d'enfants porteurs d'un autisme génétiquement déterminé ". On ne peut actuellement savoir s'il s'agit de cas exceptionnels ou si leur fréquence se révélera non négligeable. L'important est que, probablement pour la première fois, on a pu apporter la preuve d'un déficit enzymatique précis chez des enfants présentant des manifestations autistiques. De tels résultats devraient inciter d'autres laboratoires à tenter de confirmer cette découverte, et à rechercher d'autres lésions biochimiques qui ne seraient pas nécessairement limitées aux voies de synthèse des purines.

Jaeken J, Urn den Berghe G. An infantile autistic syndrome characterised by the presence of succinylpurines in body fluids. Lancet 1984 ; ii: $1058-61$.
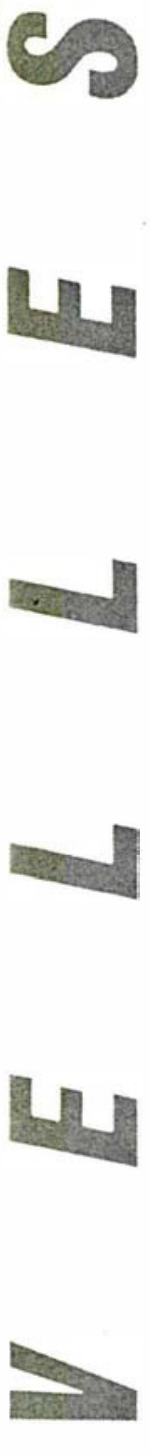

8

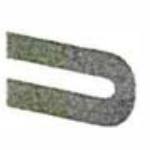

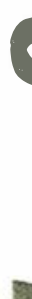
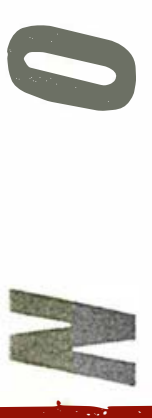